\title{
Prospects of environmentally safe use of renewable energy sources in the sustainable tourism development of the Carpathian region of Ukraine
}

\author{
Oleh Mandryk ${ }^{1}$, Nataliia Moskalchuk ${ }^{1, *}$, Liudmyla Arkhypova ${ }^{2}$, Mykola Prykhodko ${ }^{3}$, and Olena Pobigun ${ }^{2}$ \\ ${ }^{1}$ Ivano-Frankivsk National Technical University of Oil and Gas, Ecology Department, Ivano-Frankivsk, 76019, Ukraine \\ ${ }^{2}$ Ivano-Frankivsk National Technical University of Oil and Gas, Tourism Department, Ivano-Frankivsk, 76019, Ukraine \\ ${ }^{3}$ Ivano-Frankivsk National Technical University of Oil and Gas, Department of Geodesy and Land Management, Ivano-Frankivsk, \\ 76019, Ukraine
}

\begin{abstract}
The use of renewable energy in sustainable tourism development of the region is substantiated in the paper. There are three stages in selecting areas for projects on renewable energy sources: selection of the potentially suitable area; consideration of exclusion criteria; detailed assessment of potential areas. The impact factors on spatial constraints and the opportunities for building solar power plants, on the parameters of sustainable tourism development in the Carpathian region were determined. New research findings were obtained, the result of which was the concept and cartographic models of the environmentally safe location of renewable energy objects. New methods and methodological recommendations for the development of renewable energy in the Carpathian region were described as prospective taking into account the constraints on the parameters of environmental safety and tourist use of the territory.
\end{abstract}

\section{Introduction}

It is known that in Ukraine, as well as in many countries in the world, there is the need for alternative energy due to the lack of conventional energy sources. At present, it is believed that the use of renewable energy sources is one of the ways to solve this problem. The relevance of the scientific project is apparent and is related to the fact that the world community regards the use of alternative and renewable energy as one of the most promising solutions to the growing problems of energy supply. Solar energy is one of the most promising alternative sources of energy. Considering the dynamics of reducing the cost of electricity, generated by the sun, it is strategically important for Ukraine to develop these directions in the future, especially in such a difficult economic situation.

Many works are devoted to the efficiency and expediency of the use of solar energy $[1,2]$. Substantial results are obtained in the Institute of Semiconductors Physics of NAS of Ukraine, in the Kyiv, Odesa, Uzhhorod and Chernivtsi Universities, on some industrial enterprises ("Pillar", "Quasar"), in other Ukrainian laboratories.

All of them state, that the use of alternative energy sources in Ukraine, mainly solar energy, will undoubtedly bring benefits [3].

The prospects of introducing renewable energy sources should be considered in the light of trends in tourism potential, represented by the number of historical, cultural and natural resources, as well as the level of tourism infrastructure development, which mainly depends on the available number of catering establishments and accommodation.

In general, the current state of analysis and assessment of solar energy sources is considered in the article. The main types of works concerning the natural resources of renewable energy, the scientific achievements related to the use of natural resources for the development of alternative energy, which contain a general and special description of renewable energy resources, ways of their use and evaluation have been singled out and analyzed. The conducted analysis has shown that today more and more authors devote their works to the systematization and improvement of non-traditional energy sources and complex calculation of the options, by means of which energy can be obtained [4-6].

Very often, the necessary data on solar energy are absent, and for this purpose the analytical dependencies are used, which help to solve the set tasks with sufficient accuracy.

Another source of sun radiation of a certain territory is the results of long-term NASA research, including satellite measurement, atmospheric design, and surface studies. In this model, such factors as climatic zones, reflectance, turbidity, precipitation, and aerosols in the atmosphere are used in atmospheric design [7].

Renewable energy sources help to solve the problem of the sustainable development of mankind by reducing air, water and soil pollution, but they can also have an environmental impact.

In addition to favorable climatic characteristics, spatial planning of the area with environmental

* Corresponding author: moskalcuknatalia@gmail.com 
constraints is important, as it can help to avoid the obstacles to planned activities, environmental impact or public dissatisfaction.

\section{Problem statement}

The purpose of the paper is to substantiate the feasibility of introducing solar energy resources in the Carpathian region and to prove that there are no objective resource obstacles to the development of solar energy in the Carpathian region. Recently, there has been a growing interest in using photovoltaic panels to produce electricity by converting solar energy.

Along with other renewable energy devices, the photovoltaic panels have several advantages, including the simplicity of design and structure, light weight and dimensions, and long life. However, their main disadvantages are their low efficiency, the instability of electricity due to weather conditions and the dependence of output power on the incidence angle of sunlight on the absorbing panel. To use solar installations, it is necessary to have data on the distribution of solar radiation in the area. The administrative Carpathian region includes Ivano-Frankivsk, Lviv, Zakarpattia and Chernivtsi oblasts.

There arises the need to assess the tourist potential of the territories. In this regard, it is necessary to develop a model of tourism organization in the region and identify the territories that require priority concentration of efforts and resources for their development, protected areas and territories where tourism infrastructure is inappropriate [8].

Thus, there is a need to solve the following tasks: to accumulate the data on solar radiation intensity in each tourist region; to process the data and determine probable characteristics of the intensity of solar radiation distribution $[9,10]$.

The introduction of new facilities, including solar power plants, requires a complex of pre-investment research, which should include the environmental impact assessment in addition to assessing the energy potential. The environmental impact assessment is usually carried out in three stages:

1. determination of first-line impacts (screening);

2. development of a complex of mitigation measures;

3. impact significance assessment;

4. decision making.

The notion of "impact significance" is a core concept of the Directive 2011/92/EU "On the assessment of the effects of certain public and private projects on the environment" [11], which was introduced in the Ukrainian legislation in December 2017 by the Law of Ukraine "On Environmental Impact Assessment" (EIA) [12]. Article 3 of the Directive requires that "the environmental impact assessment shall identify, describe and assess in an appropriate manner, in the light of each individual case" [11]. For this reason, it is necessary to justify the impact significance assessment, in particular it is important to establish a transparent methodology that explains the approaches of assessment and its practical application.
The impact significance assessment should not be the exclusive prerogative of professionals: the significance should be determined in such a way as to reflect what is assessed in the environment for the authorities and the public. A common approach used in EIA is a multicriteria analysis [13]. The multi-criteria comparative analysis, which uses different methods, makes it possible to assess the significance, when it cannot be done using standard absolute methods, and to compare different impacts.

\section{Results and discussion}

\subsection{Method of determining the prospects of the oblasts of the Carpathian region for the implementation of renewable energy sources}

The Carpathian region development strategy is the tourism industry. At present, the development of tourism industry requires an ecologically-oriented attitude to natural resources and their use.

Having analyzed the available methods for assessing the tourism potential $[14,15]$, we propose our own point assessment, based on the integrated ranking of the territories. We propose to introduce an appropriate assessment of tourism potential in accordance with the integrated rating of individual oblasts of the Carpathian region on a scale (1-1.7 - low; 1.8-3.3 - medium; 3.45.0 - high) for each area, based on a maximum score of 5 points.

The components of tourism potential are the amount of historical and cultural resources $(\mathrm{K} h c)$, natural resources $(\mathrm{K} n)$ and the main components of tourism infrastructure (Kinf) - accommodation and catering establishments.

Taking into account the number of these units in the oblasts of the region, we introduce a degree of ranking $(\mathrm{R})$ of historical, cultural, natural resources and infrastructure $-R_{\mathrm{K} h c}, R_{\mathrm{K} n}, R_{\mathrm{Kinf}}$, respectively.

For each of these components, we set the coefficients of significance (S), respectively:

$$
S_{K h c}=0,3, S_{K n}=0,3, S_{K i n f}
$$

The integral rank for each region is determined by the sum of the products of the degree of ranking and the importance of each component in Equation 1:

$$
I=R_{K h c} * S_{K h c}+R_{K n} * S_{K n}+R_{K i n f} * S_{K i n f}
$$

Based on the maximum score of 5 points, we determine the point estimate of the tourist potential by the integrated ranking according to the scale:

-1-1.7 - low;

-1.8-3.3 - medium

-3.4-5.0 - high.

According to the point evaluation of the tourist potential, we have determined the levels of prospects of the oblasts for introducing renewable energy sources in tourist complexes in each of the oblasts of the Carpathian region (Figure 1). 


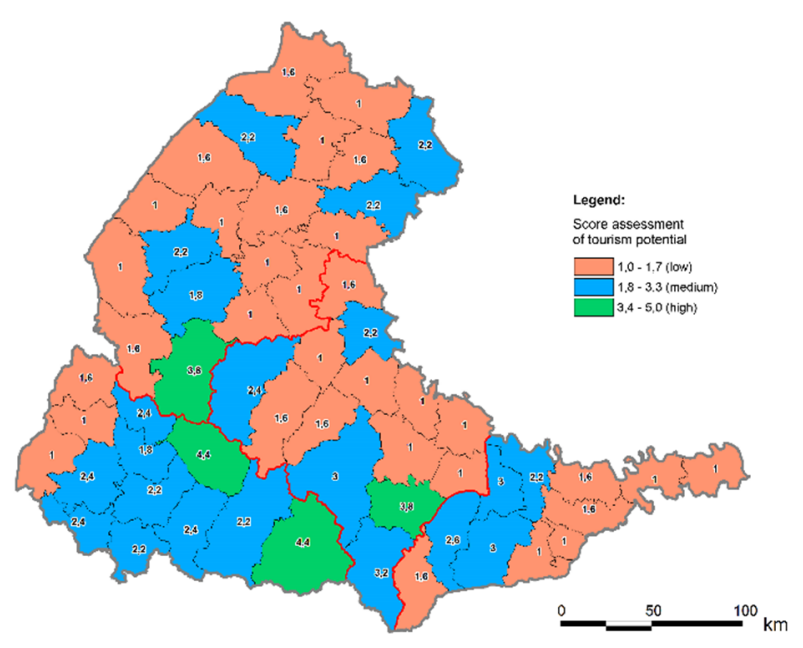

Fig. 1. Estimation of tourist potential by the integrated ranking of individual oblasts of the Carpathian region of Ukraine.

In Ivano-Frankivsk oblast the highest level of prospects can be expected in Kosiv region; medium - in Verkhovyna, Halych, Dolyna, Nadvina, Yaremche regions, Ivano-Frankivsk; low - in Bohorodchany, Horodenka, Kalush, Kolomyia, Rohatyn, Rozhniativ, Sniatyn, Tysmenytsia, Tlumach regions.

In the case of Lviv oblast, the highest level of prospects can be expected in Skole region and the outskirts of Lviv; medium - in Brody, Drohobych, Zhovkva, Zolochiv, Sambir regions; low - in Buh, Horodok, Zhydachiv, Kamianka-Buzka, Mykolaiv, Mostysky, Peremyshliany, Pustomytiv, Radekhiv, Sokal, Starosambir, Stryi, Turkiv and Yavoriv regions.

In Zakarpattia oblast the highest level of prospects is in Mizhhirria and Rakhiv regions; medium - in Berehovo, Vynohradiv, Volovetsk, Irshava, Mukachevo, Svaliava, Tiachiv, Khust regions; low - in Velyki Berezniany, Perechyn and Uzhhorod regions.

In Chernivtsi oblast the highest level of prospects are on the outskirts of Chernivtsi; medium - in Vyzhnytsia, Zastavna, Kitsman, Storozhynets regions; low - in Hertsaiv, Hlybochytsia, Kelmintsi, Novoselytsia, Putyvl, Sokyriany and Khotyn regions.

\subsection{Method of determining the prospects of the oblasts of the Carpathian region for the implementation of renewable energy sources}

Having identified which areas are promising in terms of tourism industry development, we can envisage the appropriate scenarios for the introduction of renewable energy sources, attracting internal and external investments in tourism activities related to the sphere of the economic complex of the region. The regional average annual values of the total solar radiation within the whole Carpathian region on the horizontal (underlying) surface are presented on the Map Info map, that we developed in GIS, in Figure 2, containing 10 color gradations. The results indicate a gradual decrease in the quantitative indicators in the direction of the south-east-northwest.

The efficiency of light-absorbing panels operation in the Carpathian region has been studied on the basis of the
Ivano-Frankivsk National Technical University of Oil and Gas since April 2015. Daily measurements of electricity produced and meteorological indices are carried out.

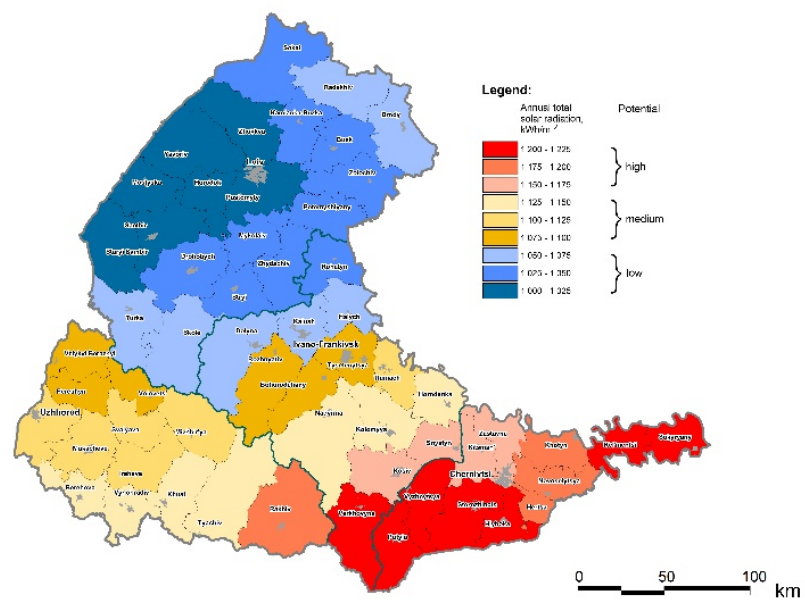

Fig. 2. Annual total solar radiation in the Carpathian region of Ukraine.

The experimental study has been conducted; the obtained results have been statistically processed. The functional dependence of generating electricity on meteorological parameters has been identified, namely, cloudiness, probability of precipitation, air temperature, atmospheric pressure, humidity and wind speed.

According to the results, the amount of obtained energy substantially depends on the indexes of cloudiness (Figure 3), humidity (Figure 4), and air temperature (Figure 5).

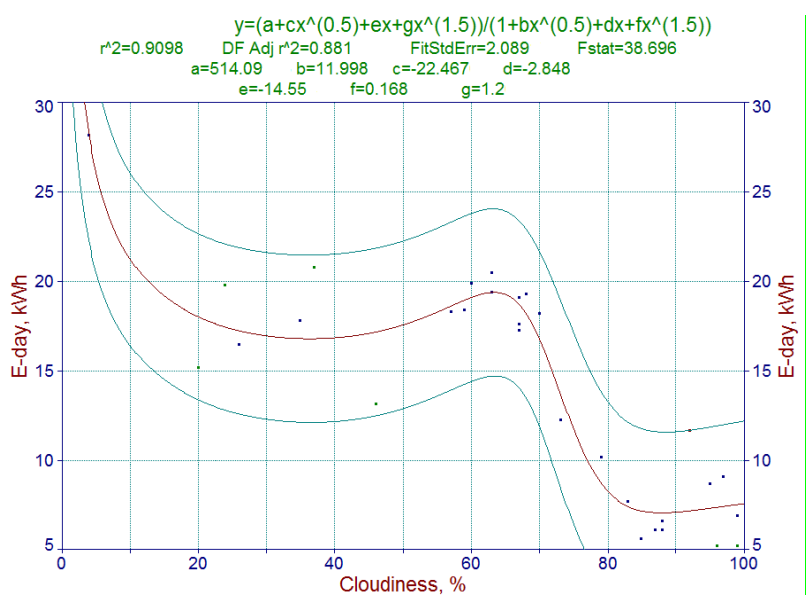

Fig. 3. Functional dependency of electricity generation by the photovoltaic panels on the level of cloudiness in IvanoFrankivsk.

Functional dependencies were established by processing long-term observation data using TableCurve 2D software. The program uses the basic criteria of statistics: the sum of squares of the mean, sum of squares of errors (residuals), degree of freedom calculated depending on the number of model parameters, standard error, coefficient of determination $\left(\mathrm{r}^{2}\right)$, coefficient of determination adjusted for the degree of freedom $\left(\mathrm{DF} \mathrm{r}^{2}\right)$, and F-statistics (Fisher test). 


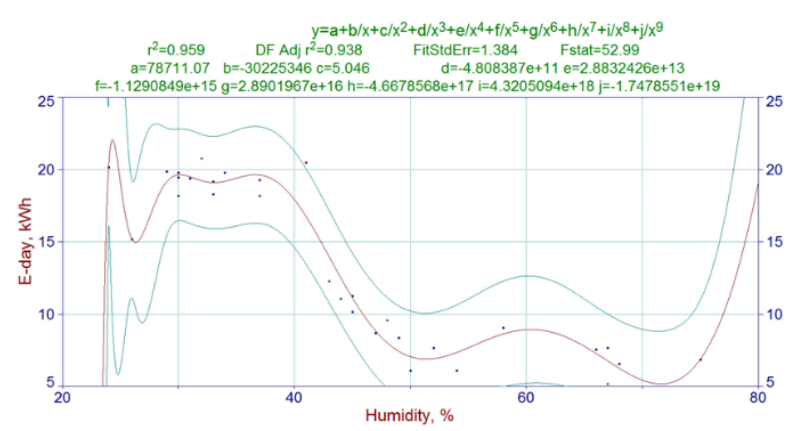

Fig. 4. Functional dependency of electricity generation by the photovoltaic panels on the level of humidity in IvanoFrankivsk.

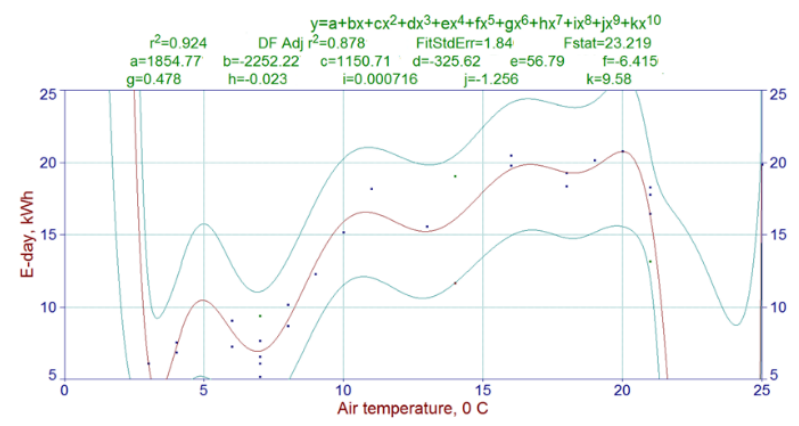

Fig. 5. Functional dependency of electricity generation by the photovoltaic panels on the air temperature in Ivano-Frankivsk.

The values of the coefficient of determination were estimated using the F-distribution quantile tables and the tables of values of coefficients. The critical values of the Fisher test were defined according to standard tables. The hypothesis (existence of a close dependence) was rejected if the value found in the table (Fstatt) was greater than the calculated (Fstatm), and was accepted as the one that was confirmed if Fstatt $<$ Fstatm. In three cases (Figures 3, 4, 5 ), the hypothesis was confirmed, provided that the significance level was accepted at $1 \%$.

However, there is no direct correlation between the indices of atmospheric pressure and wind speed. In two cases (Figures 6,7) the hypothesis was rejected, provided that the significance level was accepted at the level of $1 \%$. The critical values of the Fisher test corresponded to standard tables. The hypothesis (existence of close dependence) was rejected because the value found in the table (Fstatt) was larger than the calculated one (Fstatm).

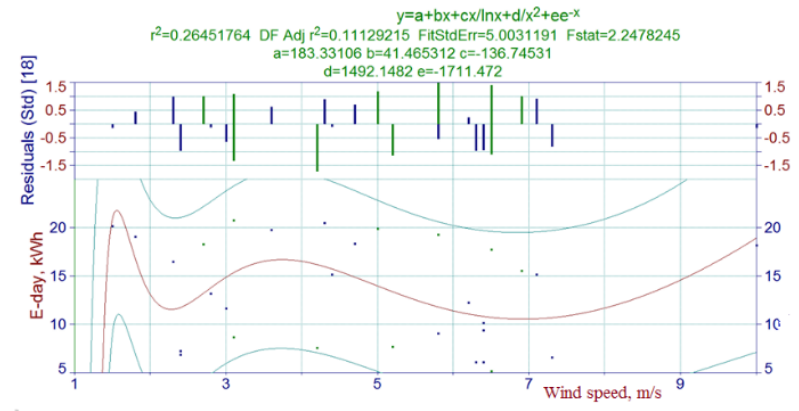

Fig. 6. Results of processing the experimental data of measurements of electricity production by photovoltaic panels and wind speed in Ivano-Frankivsk.

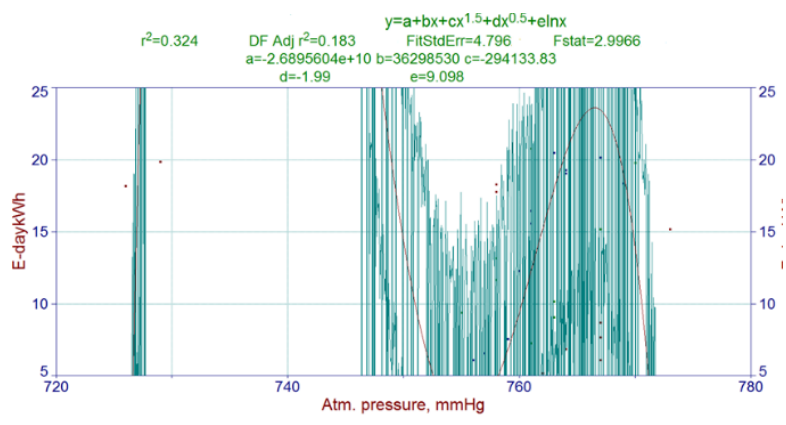

Fig. 7. Results of processing the experimental data of measurements of electricity production by photovoltaic panels and atmospheric pressure in Ivano-Frankivsk.

Therefore, based on the obtained experimental data and statistical meteorological data, the dependency curves of electricity production with the help of a light-absorbing panel on weather conditions were developed, which made it possible to perform forecast calculations.

The scientific novelty of the performed research is that we obtained significant functional dependencies of electricity production by means of a light-absorbing panel on the air temperature, cloudiness, relative humidity for local conditions of Ivano-Frankivsk oblast.

\subsection{Method for environmental impact significance assessment of renewable energy}

The suggested method for environmental impact significance assessment is based on the requirements of the national legislation for the components of the Environmental Impact Assessment report [12], the recommendations of the EU guidelines on Environmental Impact Assessment [13, 16], national guidelines on the implementation of the Strategic Environmental Assessment (SEA) [17], data of the Strategic Environmental Review conducted by Ukraine Sustainable Energy Lending Facility (USELF) [18]. In particular, the SEA guidelines recommend using a methodological approach to significance assessment that is based on the evaluation of all identified impacts by uniform qualitative and quantitative criteria that reflect the magnitude of impact (including intensity, spatial and temporal coverage, reversibility, probability of occurrence) sensitivity of the recipient.

The proposed method concerns the impact of the significance assessment of renewable energy, in particular solar power plants, on the environment and is carried out after screening and mitigation measures.

Due to the fact that many factors impacting the natural and socioeconomic environment cannot be quantified, a rating method of impact assessment is proposed, which allows comparing different types of impacts using the matrix method.

Impact significance is assessed in points. The methodology is based on the four specified parameters of impact: probability, extension, duration, and intensity.

The significance assessment enables the business entity to indicate the need for additional mitigation measures as well as to inform the competent authority, local authority and the public about the most significant 
adverse impacts. The results of such assessment will be well understood by all stakeholders as they imply three levels of significance - low, medium and high impact.

The assessment of impacts on the natural environment is carried out according to individual components: climate, atmospheric air, geological environment, soil, water; flora, fauna and biodiversity [19]. The impact assessment on the socioeconomic environment is carried out based on the following components: landscape, human health, socioeconomic situation (employment, communal infrastructure, transport, resources use), historical and cultural heritage.

For the natural environment, zero impact is not taken into account, as any activity will have an effect on the natural environment. Zero impact will only be in the absence of planned activities. The significance rank for each parameter is estimated according to the criteria suggested in Tables 1-4.

Table 1. Criteria for the significance of the impact probability on the natural environment.

\begin{tabular}{|c|c|c|}
\hline Gradation & Impact probability, \% & Point \\
\hline Very low probability & $<10$ & 1 \\
\hline Low probability & $10-50$ & 2 \\
\hline Moderate probability & $50-90$ & 3 \\
\hline High probability & $>90$ & 4 \\
\hline
\end{tabular}

Table 2. Criteria for the significance of impact spread on the natural environment.

\begin{tabular}{|c|c|c|}
\hline Gradation & Impact spread & Point \\
\hline Site & Facies, tracts $/<1 \mathrm{~km}^{2}$ & 1 \\
\hline Local & Groups of tracts, terrain $/ 1-10 \mathrm{~km}^{2}$ & 2 \\
\hline Landscape & Landscape $/ 10-100 \mathrm{~km}^{2}$ & 3 \\
\hline Regional & $\begin{array}{c}\text { Landscape districts, provinces } / \\
>100 \mathrm{~km}^{2}\end{array}$ & 4 \\
\hline
\end{tabular}

Table 3. Criteria for the significance of impact duration on the natural environment.

\begin{tabular}{|c|c|c|}
\hline Gradation & Impact duration & Point \\
\hline Short-term & Up to 3 months & 1 \\
\hline Medium-term & $\begin{array}{c}\text { From 3 months to 1 year / Stage } \\
\text { of construction }\end{array}$ & 2 \\
\hline Long-term & From 1 to 3 years / Construction & 3 \\
\hline $\begin{array}{c}\text { Very long-term / } \\
\text { (permanent) }\end{array}$ & More than 3 years / Operation & 4 \\
\hline
\end{tabular}

To assess the whole set of consequences of the planned activity on the social and economic conditions, a 5-level ranking with 0 to 4 points is proposed, with a negative and positive sign, both negative and positive factors of impact are ranked.

Each ranking of impact on the components of the socioeconomic environment is determined by the relevant criteria in Tables 5-8.

The impact significance is an integrated (integral) estimate. Impact significance assessment is carried out in several stages.

Stage 1. To determine the impact significance on the individual environmental components, it is necessary to use Tables 1-8 with the criteria of impact and Equation 2.

The impact significance on $i$-th environmental component is determined as follows:

$$
Q_{i}=Q_{i}^{p} \cdot Q_{i}^{s} \cdot Q_{i}^{t} \cdot Q_{i}^{j}
$$

$Q_{i}^{p}$ - a point of impact probability on $i$-th environmental component;

$Q_{i}^{S}-$ a point of impact spread on $i$-th environmental component;

$Q_{i}^{t}$ - a point of impact duration on $i$-th environmental component;

$Q_{i}^{j}$ - a point of impact intensity on $i$-th environmental component.

Table 4. Criteria for the significance of impact intensity on the natural environment.

\begin{tabular}{|c|c|c|}
\hline Gradation & Impact intensity & Point \\
\hline $\begin{array}{c}\text { No } \\
\text { intensity }\end{array}$ & $\begin{array}{c}\text { Changes in the natural environment do not } \\
\text { exceed the existing limits of natural } \\
\text { variability / Less than } 10 \% \text { of the object } \\
\text { changes }\end{array}$ & 1 \\
\hline $\begin{array}{c}\text { Low } \\
\text { intensity }\end{array}$ & $\begin{array}{l}\text { Changes in the natural environment go } \\
\text { beyond the limits of natural variability, the } \\
\text { natural environment is completely self- } \\
\text { healing / } 10-50 \% \text { of the object changes }\end{array}$ & 2 \\
\hline $\begin{array}{l}\text { Moderate } \\
\text { intensity }\end{array}$ & $\begin{array}{l}\text { Changes in the natural environment, which } \\
\text { exceed the limits of natural variability, } \\
\text { violate the individual components of the } \\
\text { natural environment. The natural } \\
\text { environment retains the ability to self- } \\
\text { healing / } 50-90 \% \text { of the object changes }\end{array}$ & 3 \\
\hline $\begin{array}{l}\text { High } \\
\text { intensity }\end{array}$ & $\begin{array}{c}\text { Changes in the natural environment result } \\
\text { in significant damage to the components of } \\
\text { the environment or ecosystems. Separate } \\
\text { components of the natural environment } \\
\text { lose their ability to self-healing / More } \\
\text { than } 90 \% \text { of the object changes }\end{array}$ & 4 \\
\hline
\end{tabular}

Table 5. Criteria for the significance of impact probability on the socioeconomic environment.

\begin{tabular}{|c|c|c|}
\hline Gradation & Impact probability, \% & Point \\
\hline Zero impact & no impact & 0 \\
\hline Very low probability & $<10$ & 1 \\
\hline Low probability & $10-50$ & 2 \\
\hline Moderate probability & $50-90$ & 3 \\
\hline High probability & $>90$ & 4 \\
\hline
\end{tabular}

Table 6. Criteria for the significance of impact spread on the socioeconomic environment.

\begin{tabular}{|c|c|c|}
\hline Gradation & Impact extension & Point \\
\hline Zero impact & no impact & 0 \\
\hline Site & Site of the object & 1 \\
\hline Local & Adjacent settlements & 2 \\
\hline District & One or more administrative districts & 3 \\
\hline Regional & Region & 4 \\
\hline
\end{tabular}

Table 7. Criteria for the significance of the impact duration on the socioeconomic environment.

\begin{tabular}{|c|c|c|}
\hline Gradation & Impact duration & Point \\
\hline Zero impact & no impact & 0 \\
\hline Short-term & Up to 3 months & 1 \\
\hline Medium-term & $\begin{array}{c}\text { From 3 months to 1 year / Stage } \\
\text { of construction }\end{array}$ & 2 \\
\hline Long-term & From 1 to 3 years / Construction & 3 \\
\hline $\begin{array}{c}\text { Very long-term / } \\
\text { (permanent) }\end{array}$ & More than 3 years / Operation & 4 \\
\hline
\end{tabular}


Table 8. Criteria for the significance of impact intensity on the socioeconomic environment.

\begin{tabular}{|c|c|c|}
\hline Gradation & Impact intensity & Point \\
\hline Zero impact & no impact & 0 \\
\hline $\begin{array}{l}\text { Very low } \\
\text { intensity }\end{array}$ & $\begin{array}{l}\text { Positive and negative deviations in the } \\
\text { socioeconomic environment correspond to } \\
\text { the existing fluctuations of the variability } \\
\text { of this indicator before the project } \\
\text { implementation / Less than } 10 \% \text { of the } \\
\text { object changes }\end{array}$ & 1 \\
\hline $\begin{array}{l}\text { Low } \\
\text { intensity }\end{array}$ & $\begin{array}{l}\text { Positive and negative deviations in the } \\
\text { socioeconomic environment outweigh the } \\
\text { existing trends in the changing living } \\
\text { conditions in settlements / } 10-50 \% \text { of the } \\
\text { object changes }\end{array}$ & 2 \\
\hline $\begin{array}{l}\text { Moderate } \\
\text { intensity }\end{array}$ & $\begin{array}{l}\text { Positive and negative deviations in the } \\
\text { socioeconomic environment exceed the } \\
\text { existing conditions of the medium level / } \\
50-90 \% \text { of the object changes }\end{array}$ & 3 \\
\hline $\begin{array}{c}\text { High } \\
\text { intensity }\end{array}$ & $\begin{array}{l}\text { Positive and negative deviations in the } \\
\text { socioeconomic environment outweigh the } \\
\text { existing conditions of the medium-regional } \\
\text { or inter-regional level / More than } 90 \% \text { of } \\
\text { the object changes }\end{array}$ & 4 \\
\hline
\end{tabular}

Stage 2. The level of significance is determined by the interval of values depending on the grade, obtained in the calculation, as shown in Table 9.

Table 9. Levels of impact significance on the environment.

\begin{tabular}{|c|c|}
\hline Point & Impact significance \\
\hline from +1 to +16 & Low positive impact \\
\hline from +17 to +81 & Moderate positive impact \\
\hline from +82 to +256 & High positive impact \\
\hline 0 & no impact \\
\hline from -1 to -16 & Low negative impact \\
\hline from -17 to -81 & Moderate negative impact \\
\hline from -82 to -256 & High negative impact \\
\hline
\end{tabular}

The significances are the same for different environmental components and can be compared with the identified component that is most affected.

The significance levels are determined for all environmental components. If the impact significance, determined for a particular environmental component (atmospheric air, fauna, etc.), is the only one, it is directly used to assess the resulting significance of the impact. However, in practice, one environmental component can be influenced by different sources (activities). Then the integrated (average) assessment of the significance of the impact on $i$-th environmental component will be the following:

$$
Q_{\text {int egr }}=\frac{\sum_{k=1}^{n} Q_{k i}}{n}
$$

where $Q_{k i}$ - an integrated point of $k$-th impact (type of activity) on the $i$-th environmental component;

$n$ - the number of impacts (activities) on the $i$-th component of the environment.

It is expedient to analyze the impacts on certain components of both natural and socioeconomic environments from different sources with the help of estimating matrices based on the matrix of Leopold. The integral (average) estimates for a particular component of the environment are used to determine the significance of the impact.

\section{Conclusions}

We use the estimates of tourist potential based on the integrated ranking of individual areas. As a result, it is possible to envisage the appropriate scenarios for the introduction of renewable energy sources, attraction of internal and external investments in tourist activities related to the field of economic complex.

The developed map of quantitative indicators of solar energy potential for the facilities providing renewable energy in the Carpathian region of Ukraine shows the feasibility of introducing the opportunities for using solar energy in the Carpathian region. The results of experiments showed the dependence of energy generation by photovoltaic panels on the meteorological elements of weather conditions, in particular cloudiness, humidity and air temperature. At the same time, it has no direct dependence on the atmospheric pressure and wind speed.

The method for environmental impact significance assessment of renewable energy has been proposed. It is performed after screening and mitigation measures. Due to the fact that the impact of many factors on the natural and socioeconomic environmental components cannot be quantified, a rating method of impact assessment has been proposed, which allows comparing different types of impacts using the matrix method. The methodology is based on the four specified parameters of impact: probability, spread, duration and intensity.

\section{References}

1. Godfrey Boyle (ed.), Renewable Energy: Power for a Sustainable Future (Oxford, 2012)

2. O.M. Mandryk, L.M. Arkhypova, O.V. Pobigun, O.R. Maniuk, Renewable energy sources for sustainable tourism in the Carpathian region. IOP Conf. Series: Materials Science and Engineering 144 (2015). doi: 10.1088/1757-899X/144/1/012007

3. V.Ye. Kolesnik, O.O. Borysovska, A.V. Pavlychenko, A.L. Shirin, Determination of trends and regularities of occurrence of emergency situations of technogenic and natural character in Ukraine. Naukovyi Visnyk Natsionalnoho Hirnychoho Universytetu 6, 124-131 (2017)

4. M.M. Biliaiev, T.I. Rusakova, V.Ye. Kolesnik, A.V. Pavlichenko, The predicted level of atmospheric air pollution in the city area affected by highways. Naukovyi Visnyk Natsionalnoho Hirnychoho Universytetu 1, 90-98 (2016)

5. V. Shmandiy, L. Bezdeneznych, O. Kharlamova, A. Sviatenko, M. Malovanyi, K. Petrushka, I. Polyuzhyn, Methods of salt content stabilization in circulating water supply systems. Chemistry \& Chemical Technology 11(2), 242-246 (2017). doi:10.23939/chcht11.02.242 
6. J. Twidell, T. Weir, Renewable Energy Resources (Taylor \& Francis Ltd., London, 2015)

7. Surface meteorology and Solar Energy (NASA 2019), https://eosweb.larc.nasa.gov. Accessed 21 Dec 2019

8. I. Kinash, L. Arkhypova, A. Polianska, O. Dzioba, U. Andrusiv, Yu. Yuras, Economic evaluation of tourism infrastructure development in Ukraine. IOP Conference Series: Materials Science and Engineering 477(1) (2018). doi:10.1088/1757899X/477/1/012020

9. Weather Statistics in Ivano-Frankivsk Oblast (2019), https://www.rp5.ua. Accessed 21 Dec 2019

10. Database of meteorological data, weather conditions (2019), https://www.gismeteo.ua. Accessed $21 \mathrm{Mar}$ 2020

11. Directive 2011/92/EU of the European Parliament and of the Council of 13 December 2011 on the assessment of the effects of certain public and private projects on the environment (European Union, 2012), https://eur-lex.europa.eu/legalcontent/EN/TXT/?uri=CELEX:02011L009220140515. Accessed 21 Mar 2020

12. Verkhovna Rada of Ukraine, Law of Ukraine 205919 of 23 May 2017 Pro otsinku vplyvu na dovkilia (On Environmental Impact Assessment) (2017), http:.zakon3.rada.gov.ua/laws/show/2059-19. Accessed 21 Mar 2020

13. Guidance on the preparation of the Environmental Impact Assessment Report (European Union, 2017), http:.ec.europa.eu/environment/eia/pdf/EIA_guidanc e_EIA_report_final.pdf. Accessed 21 Mar 2020

14. V.H. Gerasymenko (ed.), Assessment of the tourist and recreational potential of the region (ONEU, Odessa, 2016)

15. O. Molnar, O. Marchenko, F. Vazhinskyi, Estimation of the existing tourist and recreational potential of the Transcarpathian recreation zones. Scientific Bulletin of Uzhhorod National University. Economy series 24, 17-25 (2007)

16. Guidance on Scoping (European Union, 2017), http://ec.europa.eu/environment/eia/pdf/EIA guidan ce_Scoping_final.pdf. Accessed 21 Mar 2020

17. Metodychni rekomendatsii iz zdiisnenia stratehichnoi ekolohichnoi otsinky dokumentiv derzhavnoho planuvannya (Guidelines on strategic environmental assessment of state planning documents). (Ministry of ecology and natural resources of Ukraine, 2018), https://menr.gov.ua/files/docs/nakazy/2018/nakaz_2 96.pdf. Accessed 21 Mar 2020

18. Strategic Environmental Review (Ukraine Sustainable Energy Lending Facility, 2011), http://www.uself.com.ua/index.php?id=33\&L=2 . Accessed 21 Mar 2020

19. Y. Zelenko, M. Malovanyi, L. Tarasova, Optimization of heat-and-power plants water purification. Chemistry and Chemical Technology 13(2), 218-223 (2019). doi:10.23939/chcht13.02 